Rijken, P.M., Dekker, J. Clinical experience of rehabilitation therapists with chronic diseases: a quantitative approach. Clinical Rehabilitation: 1998, 12(2), 143-150

\begin{tabular}{|l|l|}
\hline $\begin{array}{l}\text { Postprint } \\
\text { Version }\end{array}$ & 1.0 \\
\hline $\begin{array}{l}\text { Journal website } \\
\text { Pubmed link }\end{array}$ & $\underline{\text { http://cre.sagepub.com/cgi/content/abstract/12/2/143 }}$ \\
\hline DOI & $\underline{10.1191 / 026921598669374346}$ \\
\hline
\end{tabular}

This is a NIVEL certified Post Print, more info at http://www.nivel.eu

\title{
Clinical experience of rehabilitation therapists with chronic diseases: a quantitative approach
}

\author{
PM RIJKEN AND J DEKKER \\ NIVEL/Netherlands Institute of Primary Health Care, Utrecht, The Netherlands
}

Address for correspondence: PM Rijken, NIVEL/Netherlands Institute of Primary Health Care, PO Box 1568, 3500 BN Utrecht, The Netherlands.

Objectives: To provide an overview of the numbers of patients with selected chronic diseases treated by rehabilitation therapists (physical therapists, occupational therapists, exercise therapists and podiatrists). The study was performed to get quantitative information on the degree to which rehabilitation therapists are experienced in the treatment of chronically ill patients.

Methods: Secondary analyses were performed on several databases containing representative data on patients treated by rehabilitation therapists. Rates per 1000 patients in the populations of these rehabilitation therapists and $90 \%$ confidence intervals were computed for patients with the following diagnoses: ischaemic heart diseases, stroke, rheumatoid arthritis, osteoarthritis, osteoporosis, multiple sclerosis, Parkinson's disease, epilepsy, headache syndromes, COPD/asthma, diabetes mellitus and chronic back pain (the size of the latter group could only be assessed in physical therapy in primary care).

Results: The largest group of chronically ill patients treated by physical therapists in primary care are patients with chronic back pain (82 per 1000). Stroke patients are the most common chronically ill patients treated by physical therapists in institutional care (157 per 1000 ) and by occupational therapists in institutional (358 per 1000) and noninstitutional care (246 per 1000). These therapists also see a variety of other chronically ill patients. Exercise therapists and podiatrists treat less patients with the selected chronic diseases.

\section{INTRODUCTION}

As in all Western countries, chronic diseases are an important health care problem in the Netherlands. Demographic developments such as the ageing of the population have led to a considerable increase in the number of people suffering from chronic diseases. Research on the noninstitutionalized Dutch population shows that the number of chronic diseases is 49 per 100 males and 69 per 100 females. ${ }^{1}$ Furthermore, the number of chronic diseases increases with age.

Chronic diseases are diseases that cannot (fully) be cured given the current state of medical science. In general, these diseases can be characterized as irreversible and longlasting. ${ }^{2}$ However, diseases with a relatively short course - due to death - are also counted as chronic diseases. Because of the diversity in causes, course, possibilities of intervention and consequences, no generally accepted definition of chronic diseases exists. ${ }^{3}$ The lack of such a 
Rijken, P.M., Dekker, J. Clinical experience of rehabilitation therapists with chronic diseases: a quantitative approach. Clinical Rehabilitation: 1998, 12(2), 143-150

definition makes it necessary to agree upon the concept of chronic diseases in another way. This is usually done by selecting a number of diseases that are generally regarded as chronic. ${ }^{4}$

The efficacy of medical interventions for chronic diseases is, by definition, limited. Mostly the purpose of medical treatment of chronic diseases is palliative rather than curative. Most attention is paid to maintenance or improvement of functional health of the patient and less to recovery of the illness. Medical interventions directed at improving functional health are, for instance, reconstructive surgery (implantation of artificial joints) in patients with rheumatoid arthritis and medication in patients suffering from Parkinson's disease. Because of the limited medical possibilities and consequently the shift in attention from recovery of the disease to functional health, the treatment of rehabilitation therapists may be of special importance for chronically ill people. ${ }^{5}$ Most types of care of rehabilitation therapists are primarily aimed at reducing the negative functional consequences of disease.

Rehabilitation therapists evaluate problems of functional health, for instance pain, muscle strength, and basic motor skills. In fact, a 'functional diagnosis' is made in order to select treatment goals and appropriate interventions. For the purpose of research in rehabilitation disciplines, the International Classification of Impairments, Disabilities and Handicaps ${ }^{6}$ has proved to be useful in formulating functional diagnoses and treatment goals. ${ }^{7}$ The treatment of physical therapists, exercise therapists, speech therapists and podiatrists is primarily aimed at alleviation of impairments, for instance pain, fatigue or joint range of motion. In contrast, occupational therapists pay more attention to a patient's disabilities, such as disabilities in activities of daily living. ${ }^{7}$ The fact that the functional health of a patient is the main objective of rehabilitation therapists stresses their common interest in the care for chronically ill people. However, there may be large differences between rehabilitation disciplines when it comes to which chronically ill patients are treated.

Until now, empirical data on the role of rehabilitation therapists in the care for chronically ill patients have been scarce. Several studies in which rehabilitation disciplines in the Dutch health care system were described suggest that chronic diseases are often indications for referral to physical therapy and occupational therapy.${ }^{8.9}$ However, a systematic investigation of the extent to which rehabilitation therapists treat chronically ill patients has not taken place. Therefore, there is a lack of knowledge on the degree to which rehabilitation therapists are familiar with several chronic diseases. Insight into the relations between rehabilitation disciplines and chronic diseases makes it possible to define target groups of rehabilitation therapists that can be involved in activities aimed at improving the quality of life of chronically ill people. Therefore, our main purpose was to provide a quantitative overview of the patients with selected chronic diseases treated by rehabilitation therapists.

Twelve chronic diseases were included in the study: ischaemic heart diseases (including myocardial infarction), stroke, rheumatoid arthritis, osteoarthritis, osteoporosis, multiple sclerosis, Parkinson's disease, epilepsy, headache syndromes, chronic obstructive pulmonary disease/ asthma, diabetes mellitus and chronic back pain. These diseases were selected because of their frequent occurrence in the general population and/or their heavy burden on health care. ${ }^{10,11}$

\section{METHODS}

\section{Data}

Secondary analyses were performed on several databases (see Appendix 1) concerning diagnostic and therapeutic data on patients treated by physical therapists, occupational therapists, exercise therapists (Cesar and Mensendieck therapists), and podiatrists. Although a database of patients treated by speech therapists was also available, this database was not included for practical reasons: the number of adult patients - in which the selected chronic 
diseases most frequently occur - proved to be very small. In all cases data had been collected using a standard registration form concerning patient characteristics, indications for referral/medical diagnoses and treatment characteristics.

The samples were confined to patients for whom at least one indication for referral/medical diagnosis had been recorded; patients without any recorded indication for referral were excluded. Moreover, in order to have more comparable patient samples, only patients aged 25 years and older were included. Because of these criteria, the samples were reduced to 14032 (physical therapy, primary care), 1721 (physical therapy, institutional care), 623 (occupational therapy, noninstitutional care), 930 (occupational therapy, institutional care), 1247 (exercise therapy, primary care), and 309 patients (podiatry, primary care).

The indications for referral/medical diagnoses had been recorded in the databases according to international classification systems: International Classification of Primary Care (ICPC), ${ }^{12}$ International Classification of Diseases 9th revision - clinical modification (ICD-9$\mathrm{CM})^{13}$, International Classification of Diseases 10th revision - clinical modification (ICD10-CM) ${ }^{14}$ We selected the 12 chronic diseases on the basis of their codes of ICPC, ICD-9CM and ICD-10-CM (see Appendix 2). In the case of chronic back pain we used an additional criterion in order to select chronically ill patients only; patients had to suffer from back pain for at least three months prior to the start of the rehabilitation treatment. Since the duration of the back complaints had only been registered in the database of physical therapy in primary care, analyses of chronic back pain were performed only on this database.

\section{Statistical analysis}

Analyses were performed on each database separately using SPSS statistical package. We computed the numbers of patients with the selected chronic diseases. Based on these numbers, we assessed the number of patients with a chronic disease per 1000 patients (rate). In order to assess the reliability of these rates, we computed $90 \%$ confidence intervals of the binomial distribution. In the case of large confidence intervals, the assessed rates are not very informative; the 'true' rates may deviate considerably from the rates found in the samples. Small confidence intervals indicate more precise assessments of the population rates. $^{15}$

\section{RESULTS}

Table 1 shows the numbers of patients with the selected chronic diseases (rates) that were treated by rehabilitation therapists working in primary care and in institutions.

\section{[TABLE 1]}

\section{Physical therapy}

The most frequently treated chronic diseases by physical therapists working in primary care are musculoskeletal diseases such as chronic back pain, osteoarthritis and rheumatoid arthritis.

Physical therapists working in institutions treat a variety of patients with chronic diseases. Besides the musculoskeletal ailments already mentioned, they treat patients with stroke. COPD/asthma, ischaemic heart diseases, Parkinson's disease and, to a less degree, patients with multiple sclerosis. 
Rijken, P.M., Dekker, J. Clinical experience of rehabilitation therapists with chronic diseases: a quantitative approach. Clinical Rehabilitation: 1998, 12(2), 143-150

\section{Occupational therapy}

The patient populations of occupational therapists working in institutional or noninstitutional care are quite comparable with regard to medical diagnosis. The great majority of the chronically ill patients suffer from (complications of) stroke. Also, rheumatoid arthritis and osteoarthritis are common ailments of occupational therapy patients. Occupational therapists also treat patients suffering from neurological diseases, such as Parkinson's disease and multiple sclerosis, diabetic patients and patients with COPD/asthma.

\section{Exercise therapy}

The largest group of chronically ill patients treated by exercise therapists consists of patients suffering from headache syndromes. Besides, patients with osteoarthritis or osteoporosis form a substantial part of the patient population of exercise therapists.

\section{Podiatry}

The largest group of chronically ill patients seen by podiatrists consists of diabetic patients. Furthermore, podiatrists treat patients suffering from osteoarthritis.

\section{DISCUSSION}

Chronic diseases are a considerable burden on Western health care systems. One of the common characteristics of chronic diseases is the fact that these diseases cannot fully be cured. This implicates that patients and health care professionals should strive for optimal functional health rather than for absence of pathology. Rehabilitation therapists are primarily concerned with the functional consequences of disease, and therefore, are expected to play an important role in the care for chronically ill people. However, so far these expectations have not been tested. This study was performed to get more insight into the extent to which rehabilitation therapists are experienced in the treatment of chronic diseases.

Our results show that physical therapists working in primary care treat relatively few chronically ill patients. As far as they treat chronically ill patients, they are mainly concerned with the treatment of patients with chronic musculoskeletal diseases. Physical therapists providing institutional care have a more varied patient group with chronic diseases. A relatively large part of their patient group consists of patients suffering from stroke, COPD/asthma, ischaemic heart diseases, Parkinson's disease and multiple sclerosis, besides the already mentioned musculoskeletal diseases. In the case of stroke and ischaemic heart diseases, physical therapy can be considered a usual part of the rehabilitation programme after a stroke or myocardial infarction. Physical therapy for COPD/asthma patients has been aimed at the treatment of the obstruction of the bronchial tubes, alteration of breathing and improving the general physical condition of the patient. ${ }^{16}$ The treatment of patients with Parkinson's disease and multiple sclerosis by physical therapists is in accordance with treatment recommendations for these diseases; physical therapy is considered important to maintain maximal functional capacity. ${ }^{17}$

Occupational therapists working in institutional as well as noninstitutional care treat a multiplicity of chronically ill patients. The largest group consists of patients suffering from stroke. Stroke can be highly disabling because of the many complications, for instance paralyses, aphasia and cognitive impairments. Occupational therapy can be used to improve sensorimotor and cognitive functions. ${ }^{18}$ Besides patients with stroke, patients with chronic musculoskeletal diseases and patients with neurological diseases are also treated relatively often by occupational therapists. These diseases are also known as very disabling. ${ }^{10}$ When counting the numbers of patients with the selected chronic diseases per 1000 patients treated 
Rijken, P.M., Dekker, J. Clinical experience of rehabilitation therapists with chronic diseases: a quantitative approach. Clinical Rehabilitation: 1998, 12(2), 143-150

by occupational therapists, it appears that patients with chronic diseases form more than half of the total patient group.

Exercise therapists and podiatrists provide care for specific patient groups such as patients with headache syndromes or musculoskeletal diseases (exercise therapy) and diabetic patients (podiatry). In the case of diabetes mellitus, impairments of lower extremities, generally called the 'diabetic foot', can be held responsible for the frequent use of podiatary by diabetic patients. With regard to exercise therapy, one should notice that we were not able to assess the number of patients with chronic back pain treated by exercise therapists. It can be expected, however, that especially these patients form a substantial part of the patient population of exercise therapists.

Some remarks should be made with regard to the external validity of the results. In the first place, rehabilitation therapists are not always informed by physicians about the medical diagnoses of the patients referred. In some cases an indication for referral/medical diagnosis was simply not present: in all databases, indications for referral were missing in less than $10 \%$ of the patients. The podiatry database was an exception; the percentage of patients without a registered indication for referral was very high (56\%). Cases without at least one indication for referral/ medical diagnosis were excluded from the study. It is not clear whether this measure led to bias in our findings concerning the treatment of chronically ill patients by rehabilitation therapists.

Since we do not have indications that chronic diseases are more or, conversely, less than other ailments reported by physicians in their letters of referral, we assume that this measure did not have consequences for the results except that it reduced the number of cases involved, and thus the reliability of the results. It is also possible that in some cases only the functional consequences of a disease had been reported by physicians as indications for referral rather than the underlying diseases. Since the patients were exclusively selected on the basis of the codes corresponding with the 12 chronic diseases (except for stroke; here we also included patients on the base of codes for hemiplegia), this implicates that patients whose indications for referral had been recorded only in terms of functional problems were not included. The reader should be aware that our study did not cover all kinds of chronic diseases. Therefore, when drawing conclusions about the place that chronically ill patients occupy in rehabilitation disciplines, we have to confine ourselves to patients with the selected chronic diseases.

We conclude that especially physical therapists working in institutional care and occupational therapists are experienced in the treatment of a variety of chronic diseases. The term 'experience' in this paper refers to quantity rather than quality, since we do not have qualitative information about the treatments. Nevertheless, because of their frequent contacts with chronically ill patients, the experience of these rehabilitation therapists is indispensable for the development of activities aimed at improving the quality of life of chronically ill people. Furthermore, they are important target groups to direct intervention programmes to.

\section{REFERENCES}

1 Netherlands Central Bureau of Statistics. Netherlands Health Interview Survey 1981-1991. Den Haag, The Netherlands: SDU/CBS, 1992.

2 National Committee for Chronically III People. Meerjaren beleidsplan 1996-1999 [in

Dutch]. Zoetermeer, The Netherlands: NCCZ, 1995.

3 Elderen T van, Toorn S van der, Echteld M, Folkersma R, Maes S, Diekstra R. Kwaliteit van leven onderzoek bij somatische chronische ziek(t)en [in Dutch]. Zoetermeer, The Netherlands: NCCZ, 1994.

4 Bruin KM de, Jansen J, Verkleij $\mathrm{H}$. Leefstijlfactoren en chronische ziek(t)en. Naar een integratieve preventie-strategie [in Dutch]. Bilthoven, The Netherlands: RIVM, 1995. 
Rijken, P.M., Dekker, J. Clinical experience of rehabilitation therapists with chronic diseases: a quantitative approach. Clinical Rehabilitation: 1998, 12(2), 143-150

5 Reed RL, Gerety MB, Winograd CH. Expanded access to rehabilitation services for older people. An urgent need. J Am Geriatr Soc 1990; 38: 1055-56.

6 World Health Organization. International Classification of Impairments, Disabilities, and Handicaps. Geneva: WHO, 1980.

7 Dekker J. Application of the ICIDH in survey research on rehabilitation: the emergence of the functional diagnosis. Disabil Rehabil 1995; 17: 195-201.

8 Dekker J, Baar ME van, Curfs ECh, Kerssens JJ. Diagnosis and treatment in physical therapy: an investigation of their relationship. Phys Ther 1993; 73: 568-80.

9 Driessen MJ, Dekker J, Lankhorst GJ, Zee J van der. Diagnostic findings and treatment goals in occupational therapy in hospital based care. In: Driessen MJ. Occupational therapy in hospital based care in the Netherlands. Thesis, Vrije Universiteit, Amsterdam.

10 Bos GAM van den. The burden of chronic diseases in terms of disability, use of health care and healthy life expectancies. Eur J Public Health 1995; 5: 29-34.

11 Wagner C, Foets M, Peters L, Dekker J. Haalbaarheidsstudie patiëntenpanel chronisch zieken [in Dutch]. Utrecht, The Netherlands: NIVEL, 1996.

12 Lamberts H, Wood M eds. ICPC International Classification of Primary Care. Oxford: Oxford University Press, 1987.

13 Commission on Professional and Hospital Activities. International Classification of Diseases - 9th revision - Clinical modification. Michigan, Ann Arbor, 1979.

14 World Health Organization. International Statistical Classification of Diseases and related health problems, 10th revision. Geneva: WHO, 1992.

15 Hays WL. Statistics for the social sciences, second edition. London: Holt, Rinehart \& Winston, 1973.

16 Kottke ThE, Caspersen CJ, Hill CS. Exercise in the management and rehabilitation of selected chronic diseases. Prev Med 1984; 13: 47-65.

17 Commella CL, Stebbins GT, Brown-Toms N, Goetz ChG. Physical therapy in Parkinson's disease: A controlled clinical trial. Neurology 1984; 44: 376-78.

18 Reding MJ, McDowell F. Stroke rehabilitation. Neurol Clin 1993; 5: 601-30.

19 Kerssens JJ, Curfs ECh, Groenewegen PP. Fysiotherapie in de Nederlandse gezondheidszorg, onderzoek naar (poli)klinische fysiotherapie [in Dutch]. Utrecht, The Netherlands: NIVEL, 1987.

20 Driessen MJ, Harmsen J, Dekker J, Bosveld W, Hingstman L. Inventarisatie extramurale ergotherapie 1996 [in Dutch]. Utrecht, The Netherlands: NIVEL, 1996.

21 Zuijderduin WM, Dekker J. Impairments and disabilities in patients treated by exercise therapists. J Rehabil Sci 1994; 7: 113-20.

22 Zuijderduin WM, Dekker J. Diagnoses and interventions in podiatry. Disabil Rehabil 1996; 18: 27-34. 
Rijken, P.M., Dekker, J. Clinical experience of rehabilitation therapists with chronic diseases: a quantitative approach. Clinical Rehabilitation: 1998, 12(2), 143-150

TABLES

Table 1 Number of patients with selected chronic diseases per 1000 patients treated by rehabilitation therapists (and $90 \%$ confidence intervals)

\begin{tabular}{|c|c|c|}
\hline & \multicolumn{2}{|l|}{ Physical therapy } \\
\hline & Primary care & Institutional care \\
\hline Ischaemic heart diseases & $0.9(0.6-1.4)$ & $55.8(46.7-64.9)$ \\
\hline Stroke & $8.9(7.6-10.2)$ & $156.9(142.4-171.4)$ \\
\hline Rheumatoid arthritis & $10.2(8.8-11.6)$ & $8.7(5.0-12.4)$ \\
\hline Osteoarthritis & $40.1(7.3-42.8)$ & $42.4(34.4-50.4)$ \\
\hline Osteoporosis & $3.7(2.9-4.6)$ & $7.6(4.9-12.0)$ \\
\hline Multiple sclerosis & $1.6(1.0-2.1)$ & $23.8(17.8-29.9)$ \\
\hline Parkinson's disease & $3.1(2.3-3.8)$ & $32.0(25.0-39.0)$ \\
\hline Epilepsy & $0.2(0.1-0.6)$ & $2.9(1.5-6.1)$ \\
\hline Headache syndromes & $0.9(0.6-1.5)$ & $0.0-$ \\
\hline COPD/asthma & $8.9(7.6-10.2)$ & $57.5(48.3-66.8)$ \\
\hline Diabetes mellitus & $1.0(0.7-1.6)$ & $18.0(12.7-23.3$ \\
\hline Back pain (>3 months) & $82.2(78.3-86.0)$ & 0.0 \\
\hline Number of patients & 14032 & 1721 \\
\hline \multirow[t]{3}{*}{ Number of indic. for referral } & 22025 & 2381 \\
\hline & \multicolumn{2}{|l|}{ Occupational therapy } \\
\hline & Noninstitutional care & Institutional care \\
\hline Ischaemic heart diseases & $3.2(1.3-10.1)$ & $9.7(5.8-16.9)$ \\
\hline Stroke & $245.6(217.1-274.0)$ & $358.1(332.1-384.0)$ \\
\hline Rheumatoid arthritis & $81.9(63.7-100.0)$ & $74.2(60.0-88.4)$ \\
\hline Osteoarthritis & $147.7(124.2-171.1)$ & $62.4(49.3-75.5)$ \\
\hline Osteoporosis & $44.9(31.3-58.6)$ & $9.7(5.8-16.9)$ \\
\hline Multiple sclerosis & $32.1(20.5-43.8)$ & $29.0(20.0-38.1)$ \\
\hline Parkinson's disease & $67.4(50.8-84.0)$ & $21.5(13.7-29.4)$ \\
\hline Epilepsy & $6.4(3.2-14.7)$ & $3.2(1.5-8.3)$ \\
\hline Headache syndromes & $3.2(1.3-10.1)$ & 0.0 \\
\hline COPD/asthma & $24.1(15.0-35.6$ & $17.2(10.2-24.2)$ \\
\hline Diabetes mellitus & $27.3(16.5-38.1)$ & $39.8(29.2-50.4)$ \\
\hline Number of patients & 623 & 930 \\
\hline \multirow[t]{2}{*}{ Number of indic. for referral } & 772 & 1365 \\
\hline & $\begin{array}{l}\text { Exercise therapy } \\
\text { primary care }\end{array}$ & $\begin{array}{l}\text { Podiatry } \\
\text { primary care care }\end{array}$ \\
\hline Ischaemic heart diseases & $0.8(0.3-3.8)$ & 0.0 \\
\hline Stroke & $2.4(1.1-6.2)$ & $6.5(2.6-20.3)$ \\
\hline Rheumatoid arthritis & $5.6(3.2-10.5)$ & $3.2(1.1-15.3)$ \\
\hline Osteoarthritis & $16.8(10.8-22.9)$ & $16.2(8.4-34.0)$ \\
\hline Osteoporosis & $11.2(7.4-17.6)$ & 0.0 \\
\hline Multiple sclerosis & $0.8(0.3-3.8)$ & 0.0 \\
\hline Parkinson's disease & $1.6(0.7-5.0)$ & 0.0 \\
\hline Epilepsy & 0.0 & 0.0 \\
\hline Headache syndromes & $24.9(17.6-32.1)$ & 0.0 \\
\hline COPD/asthma & $4.8(2.6-9.5)$ & $3.2(1.1-15.3)$ \\
\hline Diabetes mellitus & 0.0 & $42.1(27.4-66.9)$ \\
\hline Number of patients & 1247 & 309 \\
\hline Number of indic. for referral & 1876 & 423 \\
\hline
\end{tabular}




\section{APPENDIX 1 - DATABASES}

\section{Physical therapy in primary care}

Data were collected from all patients applying for treatment from 1989 to 1992 ( $n=17201)$ by 83 physical therapists working in private practices. ${ }^{8}$ The sample of physical therapists was representative of the population of physical therapists working in primary care in the Netherlands. Indications for referral were classified according to ICPC criteria.

\section{Physical therapy in institutional care}

This (older) database was used, because it contained data about physical therapy practice in institutions; six general hospitals and five nursing homes. ${ }^{19}$ In 1987 data were collected from 1723 patients applying for physical therapy in the general hospitals and 1024 patients who received physical therapy in the nursing homes. The participating institutions had been selected on the basis of several criteria: inpatient as well as outpatient care, location in the western region of the Netherlands, and adequate registration of patient data in information system (general hospitals). Indications for referral were classified according to the ICD-9-CM. For the purpose of this study, patients receiving outpatient care were excluded from the sample.

\section{Occupational therapy in noninstitutional care}

Recently (i.e. 1996), occupational therapists working in primary care or working in institutions providing home care registered data of 854 patients. $^{20}$ Since the sample consisted of $84 \%$ of all institutions/practices providing occupational therapy, data of the patients were considered representative of the patient population treated by noninstitutional care. Indications for referral were classified according to the ICD-10-CM.

\section{Occupational therapy in institutional care}

In 1992/1993 data were collected by 143 occupational therapists from 1051 patients referred to occupational therapists in general hospitals, nursing homes, rehabilitation centres $(n=944$ general health care patients), psychiatric hospitals and psychiatric institutions $(n=107$ psychiatric health care patients). All patients received inpatient care. ${ }^{9}$ The participating institutions had been selected at random from a list of institutions - composed by the Dutch Association of Occupational Therapy - where occupational therapists work. Excluded were institutions for mentally handicapped, treatment of children, private practices and other kinds of ambulatory care. Indications for referral were classified according to the ICD-10-CM.

\section{Exercise therapy in primary care}

In 1992/1993 48 Cesar therapists and 52 Mensendieck therapists recorded data from 1020 and 1088 patients respectively. ${ }^{21}$ The therapists had been selected at random from the lists of the practice addresses of Cesar and Mensendieck therapists in the Netherlands. These lists were composed by the professional associations of both disciplines. The great majority of the patients were treated by exercise therapists working in primary care; a small part of the sample was treated by exercise therapists working in institutional care. In order to have a more homogeneous sample, we confined it to patients treated by exercise therapists in primary care. Indications for referral were classified according to ICD-10-CM.

\section{Podiatry in primary care}

In 1992/1993, 36 podiatrists (of whom 35 working in primary care) recorded data from 897 patients applying for podiatry. ${ }^{22}$ The participating podiatrists were a representative sample of the population of podiatrists working in the Netherlands. Again, we confined the sample to patients treated in primary care. Indications for referral were classified according to ICD-10-CM. 
Rijken, P.M., Dekker, J. Clinical experience of rehabilitation therapists with chronic diseases: a quantitative approach. Clinical Rehabilitation: 1998, 12(2), 143-150

APPENDIX 2 - SELECTED CHRONIC DISEASES AND CORRESPONDING CODES ACCORDING TO ICPC, ICD-9-CM AND ICD-10-CM

\begin{tabular}{llll}
\hline Chronic disease & ICPC code & ICD-9 code & ICD-10 code \\
\hline Ischaemic heart diseases & K74-K76 & $410-414$ & I20-I25 \\
$\begin{array}{l}\text { Stroke/cerebrovascular accident } \\
\text { (incl. hemiplegia) }\end{array}$ & K90, N9927 & $430-432,434,436$ & I60-I64, I66 \\
$\begin{array}{l}\text { Rheumatoid arthritis/allied conditions } \\
\text { Osteoarthritis }\end{array}$ & L88 & 438,342 & I69, G81 \\
Osteoporosis & L89-L91 & 714,720 & M05, M06, M08 \\
Multiple sclerosis & L95 & 715 & M80-M82 \\
Parkinson's disease & N86 & 733 & G35 \\
Epilepsy & N88 & 340 & G20-G22 \\
Migraine/cluster headache & N89-N90 & 332 & G40-G41 \\
COPD/asthma & R91, R95-R96 & 345 & G43-G44 \\
Diabetes mellitus & T90 & 346 & J41-J45, J47 \\
Back pain (>3 months) & L02-L03, L86 & 250 & E10-E14 \\
\hline
\end{tabular}

${ }^{a}$ Code assigned in this study to hemiplegia; not an official ICPC-code. 